\title{
Formation of future teachers' digital competencies in the process of online lectures
}

\author{
Natalia Lobachova ${ }^{1,{ }^{*}}$, Elzara Koykova ${ }^{1}$, and Viktoria Buzni $^{1}$ \\ ${ }^{1}$ V.I. Vernadsky Crimean Federal University, 298600, Simferopol, Russian Federation
}

\begin{abstract}
The article deals with the emotional intelligence concept as a structure-forming component of the future teacher's psychological culture. The research substantiates the need to develop this personal quality in future teachers, as well as its importance for successful professional activity. The article analyses the structural components of emotional intelligence in future teachers' personal sphere. The research provides empirical material for the primary cross-section of emotional intelligence diagnostics in the future teachers' personality structure.
\end{abstract}

\section{A problem statement}

Currently, the informatization process of society has become one of the most significant global processes of our time. Informatization as an objective regularity is being actualized in the Russian Federation and has one of its priority areas education informatization, which creates a material and methodological basis for the emergence and development of new forms of education. A promising education system should be able not only to equip the student with knowledge, but also, due to the constant and rapid knowledge updating, to form the need for continuous independent mastery of them, the skills and abilities of selfeducation, as well as an independent and creative approach to knowledge throughout a person's active life.

The research relevance is associated with a new round in the development of digitalization in various spheres of society, including educational. In the context of rapidly changing economic, socio-cultural factors, the education system as a whole is undergoing a profound transformation at all levels - from revising the requirements of the Federal State Educational Standard to their implementation in the context of the learning situation. The leading position in this process is taken by the training of qualified teachers with mobile critical thinking, ready to competently solve the set of educational tasks in specific conditions.

The works of such scientists as O.B. Akimova, A.Yu. Kvashin, N.S. Kramarenko, A.Yu. Uvarov. indicate that education workers, due to limited resources, do not have enough digital literacy, which, in general, reduces the effectiveness of their teaching work [1].

\footnotetext{
* Corresponding author: ipcs-profped@yandex.ru
} 
The constant updating of content in the online space is one of the problems that contributes to the development of a mobile approach to the selection of information from both the teacher and the students. It is not always possible to assess the relevance, scientific validity of the updated content in a short time. Therefore, using an integrative approach in the development of students' digital literacy, the teacher at the same time contributes to the development of their universal competencies. One of the ways to achieve this result is the didactic resources of an online lecture, during which the teacher organizes the work of students by setting interactive tasks aimed at developing critical thinking skills.

The digitalization problem of education is caused by a number of socio-cultural factors, among which we can single out the competence-based approach, which implies that the future teacher will go beyond the stable stereotype that information technologies are platforms with technical support for information and communication technologies.

Digital competence, like any other, presupposes the meta-subject nature of its formation, which is reflected in the work programs of the disciplines of training areas related to the future specialist' pedagogical activities (S.M. Gushchina, M.V. Grebennikova, M.P. Lapchik, E.L. Fedotova) [2, 3, 4]. Undoubtedly, the university is changing not only the content of the students' professional training, but also the education process organization: the creation of electronic educational resources on the university platforms, the constant analysis of updated content on the Internet requires the teacher to revise his teaching content from the standpoint of methodological and didactic expediency.

The publications of recent years and the situation associated with the 2020 pandemic convincingly indicate that teachers with developed digital competence are especially in demand in the labor market today. The timeliness of cognitive independence in the educational process was mentioned by O.B. Akimova, S.M. Gushchina, S.D. Karakozov $[1,2,5]$.

Today in pedagogy there is no clear definition of the "digital competence" concept. As a rule, this concept is used as a synonym for "ICT competence", "IT competence", "digital literacy".

It should be noted that these lexical units cannot act as synonyms-doublets, as "ICT competence" implies the ability to perform professional tasks using information technology (V.L. Akulenko, O.B. Zaitseva, G.I. Popova) [6, 7, 8], the ability to work with information using ICT tools (V.F. Burmakina, E.V. Melnik) [9, 10]. It is inappropriate to equate this type of competence with the "IT competence" concept, since the structure of the latter is made up of computer literacy, IT literacy, information culture [11].

The concepts of "digital competence" and "digital literacy" are also not identical, since the semantic volume of the lexeme "literacy" includes the "competence" concept as "the ability to perform activities on the basis of acquired knowledge, skills and abilities").

Following N.D. Berman, we believe that digital literacy (digital fluency) is the ability (set of knowledge, skills and abilities) to safely and effectively use digital technologies and Internet resources [12]. In a broad sense, it is the ability to use digital tools.

It should be noted that this concept consists of such components as digital security (ensuring the information confidentiality and integrity), digital consumption (the level of digital technologies availability), digital competencies.

\subsection{The purpose of the research}

The purpose of the article is to substantiate the criteria and indicators for measuring the level of digital competence and to present the results of approbation of the methodology for the digital competence formation of future teachers in the process of an online lecture. The presented diagnostic tools correspond to the selected indicators of the digital competence formation. 


\section{Materials and the research results}

In our research, the development of students' digital competencies took place exclusively in the process of online lectures; this approach determined the novelty of the obtained results. In particular, the technologies for information searching on the Internet, the willingness to use mobile communications, the ability to critically evaluate the content, checking it for reliability were assessed.

The preliminary work included the process of activating the students' independent work, with the aim of motivated inclusion in cognitive activity and the search for new forms and ways of obtaining meaningful information that forms professional competencies.

The main idea of the digital competence formation was to teach students the ability to select and process information, put forward hypotheses, make decisions based on their own thoughts, their own vision of the problem. At the cognition center is a problem that requires the work of thought to solve it. Cognitive, mental activity of the individual allows him to go beyond the information received, to build new knowledge [13, 14].

The teacher's role is to help students, stimulate them to independent reflection, discoveries, new views on the studied phenomenon, subject. At the same time, the teacher and the student remain participants in this process in an active dialogue.

During the experiment, we focused on the characteristics of modern student youth, in particular, the students' desire for mobility, the desire to receive information in an interactive and playful format, appealed to the desire of future teachers to use several streams of information simultaneously [15].

Diagnostics of the digital competencies formation that are used by students in the process of an online lecture was carried out on the basis of the following criteria and indicators:

- motivational: awareness of the need to master digital Internet portals; a strong desire to use digital resources in their educational and professional activities;

- cognitive-evaluative: knowledge of digital Internet portals with reliable information in the field of educational and professional activities; knowledge of the specifics of using digital Internet resources in their own educational activities;

- operational-reflexive: possession of the technology of searching for reliable information in the process of one's own educational and professional activities; ability to reflect.

At the ascertaining stage of the experiment, the following diagnostic tools were used:

1. Questionnaire, ranked:

a) by motivational criterion (How often do you use digital content on the Internet in your educational activities? How often do you use digital Internet resources in the process of an online lecture?)

b) by the cognitive evaluation criterion (What Internet resources do you use in your educational activities? Evaluate your degree of trust in the content on these resources on a 5-point scale. What tasks do you usually solve with the help of digital content?)

c) by operational-reflexive (What technologies do you use to search for the necessary information? What criteria do you use during choosing digital content on the Internet?)

2. Conducting a provocative lecture by the teacher online in order to determine the level of students' critical thinking and their ability to double-check the accuracy of information.

Methodology. The teacher warned the students in advance that mistakes would be deliberately made during the online lecture (5) and gave the target setting to the students to determine in which part of the lecture these shortcomings were made, suggesting a corrected version. The mistakes nature that are made is quite wide: from spelling errors in the teacher's speech to distortion of factual (textual / visual) information.

To assess the level of digital competence formation, the following levels are identified: 
- high, which is characterized by the ability to quickly navigate the information flow on a given topic during an online lecture, the ability to find quickly the necessary information in Internet resources, analyse and critically evaluate content from the point of view of reliability, the skill of a quick reaction to the lecturer's use of inaccuracies online;

- average, which is characterized by a partial ability to use Internet resources in accordance with a given topic, the ability to find relevant information on the Internet, and the ability to respond to distorted information online;

- low, which is characterized by the inability to correlate the online use of Internet resources with the set of education objectives, a fragmentary developed skill of responding to incorrect information online.

In the course of the diagnostics, it was found that $12 \%$ of students have a high level of digital competence online, $35 \%$ of students have an average level, and $53 \%$ of respondents have a low level.

Thus, the obtained results of the ascertaining experiment indicate a low level of digital competence formation among the participants of the experiment, which actualizes the need to search for the creation of pedagogical conditions and didactic tools in order to eliminate the discovered gaps in the future teacher's competence model.

The formative stage of the experiment was an approbation of the methodology for the digital competence formation of future teachers in the process of online lectures on the courses "Russian language", "Teaching methods of the Russian language", which consisted of stages: search, practical, reflective.

Expected results:

- the ability to navigate quickly the information flow on a given topic;

- the ability to find the necessary information in Internet resources;

- the ability to analyse and evaluate content critically in terms of reliability;

- the skill of quick reaction to the use of inaccuracies by the lecturer online.

At the search stage, students were asked to find Internet resources independently in the Russian language in accordance with the classification: educational sites, online educational communities; virtual dictionaries; network projects in the Russian language; thematic journals on the Russian language and its teaching methods.

Students faced the problem of differentiation of some concepts (educational site network project - network educational community). With the teacher's help, the students distinguished between these concepts, characterizing each presented resource in terms of ease of use and the presented content. Then the students exchanged information about the found resources, as a result of which each student had a card index of selected information portals. Close and relevant for student youth was the opportunity to use social networks for professional development, so many students turned to thematic groups of the VKontakte social network and were able to find interesting material for opening their virtual platforms within the Russian language subject.

At the practical stage, each student presented five selected digital resources online, which presented, in the opinion of the respondents, reliable information. The students, under the teacher's guidance, developed criteria for the selection of such Internet portals, which helped the participants in the experiment to argue their point of view. As a result of the discussion about the content reliability, the students adjusted the criteria for selecting digital sources of information. During the practical stage, students were trained to create, edit digital portfolios. During online discussions, they provided mutual assistance, suggested possible adjustments to their groupmates, as well as the structure of the digital kit.

At the reflexive stage, the participants of the experiment completed tasks in the online lecture mode, with a time limit (15-20 minutes), related to determining the reliability of the proposed information in the courses "Russian language" and "Teaching Methods of the 
Russian language". After completing the tasks, the students analysed the experience of using digital competence in the specified format within the framework of the discussion, comparing their own results of their application at the ascertaining and reflective stages of the experiment. An important aspect of the reflexive stage was the opportunity to establish communication not only with the subject teacher, but also with other subjects studying philological problems. The digital skills acquired in the process of organizing online lectures made it possible to use online tools in teaching practice.

In the process of the formative stage of the experiment, it was important to organize feedback with the students, the teacher corrected the educational process promptly, and also the basis was active communication, during which each respondent had the opportunity to individually accompany and comment during the search and analysis of educational material.

At the control stage of the experiment, a diagnostic section was carried out, at which a lecture-provocation was carried out, including tasks similar to those at the ascertaining stage (Fig.1).

\section{$\square$ Ascertaining stage $\square$ Control stage $\square$ Inequality}

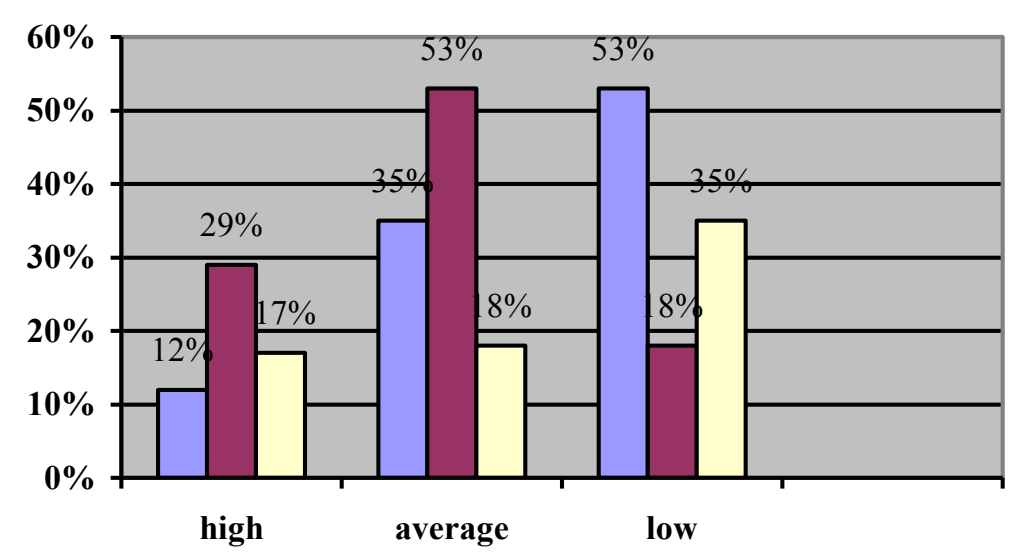

Fig. 1. Diagram of the percentage ratios of the results of the digital competence formation among students.

Summing up the above, we can conclude that the work carried out with the participants in the experiment gave positive results:

1) future teachers are motivated to develop digital competence;

2) students have developed criteria for assessing the reliability of information received via the Internet;

3) online students can quickly check and supplement the information received from the lecturer.

When choosing a structure for digital competence mastering, various models of digital competencies were taken into account, including the European digital competencies model for education, the ECDL digital skills certification program, and research work of the largest company developing testing tools ETS. Analytical reports on the development and challenges of the digital economy of the OECD, McKinsey, Microsoft, PWC, international experience of universities in integrating skills aimed at developing students' digital competencies and, in particular, the ability to work with data were taken into account. 


\section{Conclusions}

Digital competencies allow the future teacher to solve various problems in the field of using information and switching technologies. The research shows the future teachers' interest in the formation of digital skills and competencies, with the aim of organizing a digital environment in educational institutions.

Based on the obtained results, the following recommendations can be formulated: to recommend a pedagogical system for introducing the digital competencies formation in future specialists in the process of industrial training; recommend the use of the information and didactic complex as an innovative methodological basis for organizing and teaching as the basis for the digital competencies formation in future specialists.

\section{References}

1. O.B. Akimova, M.D. Shcherbin, Digital transformation of education: the timeliness of educational and cognitive independence of students, Innovative projects and programs in education, 1, 27-34 (2018)

2. S.M. Gushchina, Formation of teacher competence in the development of digital educational resources (2017)

3. M.P. Lapchik, Training of pedagogical personnel in the conditions of education informatization (Moscow, BINOM, 2013)

4. E.L. Fedotova, A.A. Fedotov, Information technologies in science and education (Moscow, FORUM, 2013)

5. S.D. Karakozov, N.I. Ryzhova, The theory of development and practice of implementing training programs in the field of information and educational systems (Moscow, 2017)

6. V.L. Akulenko, Formation of ICT competence of a subject teacher in the system of advanced training, Application of new technologies in education: Materials of the $X V$ International Conference, 344-346 (2004)

7. O.B. Zaitseva, Forming the future teachers' competence by means of innovative technologies (Bryansk, 2002)

8. G.I. Popova, Constructing electronic teaching materials in the teachers' professional training (Krasnodar, 2006)

9. V.F. Burmakina, B.Yu. Startsev, ICT competence and quality of education, Assessment of the quality of education, 2, 71-73 (2007)

10. E.G. Melnik, M.G. Melnik, Possibilities of information and communication technologies in the educational process of a medical university, International Experimental Education, 4, 189-190 (2013)

11. V.V. Sibul, Actual problems of linguistics and linguodidactics of a foreign language for business and professional communication: materials of the VII International Scientific Conference (Moscow, RUDN, 2016)

12. N.D. Berman, On the issue of digital literacy, Contemporary studies of social problems (electronic scientific journal), 8, 6-2, 35-38 (2017)

13. Russian pedagogical and psychological journal (TSU, Khabarovsk, 2017)

14. I.P. Gladilina, M.E. Krylova, Digital competences in the structure of the competencebased approach and professional development of the personality, Modern pedagogical education, 11 (2019) 
15. K.V. Sultanov, A.A. Voskresensky, Features and problems of generation $Y$ in the educational space of modern Russia, Society. Wednesday. Development (Terra Humana), 3 (36) (2015) 